\title{
Naos, clima y glaciares en el Estrecho de Magallanes durante el siglo XVI
}

\author{
María del Rosario Prieto \\ y Roberto G. Herrera \\ IANIGLA e IADIZA, CRICYT, \\ Mendoza, Argentina
}

\begin{abstract}
El objetivo de este trabajo es lograr una aproximación al clima y a los fenómenos de glaciación ocurridos en el Estrecho de Magallanes durante el siglo XVI y parte del XVII a través de registros históricos. Se complementan los resultados obtenidos por investigadores de otras disciplinas paleoclimáticas en el área, verificándose si las fuentes históricas corroboran las conclusiones de esos autores, quienes postulan un intervalo muy frío entre 1520 y 1670. Para realizar esta investigación se utilizaron los "diarios o relaciones de navegación" de los primeros marinos españoles que pasaron por el Estrecho, recopilados en su mayor parte en Archivos históricos españoles. A través de la técnica del análisis de contenido se verificó la estabilidad en el vocabulario referido al clima y los glaciares a lo largo de esas centurias y se calificó los eventos de acuerdo a su magnitud. Se determinaron diversas categorías de las cuales se han seleccionado precipitaciones sólidas y líquidas, temperatura, dirección del viento y ocurrencia de tormentas para analizar en este trabajo. Se estudió especialmente la presencia de témpanos en el Estrecho y las descripciones de los glaciares fueguinos y del sur de la Patagonia chilena como indicadores de bajas temperaturas. Se concluye que existen referencias directas a la presencia de témpanos proveniente de glaciares en el Estrecho, sólo en la segunda mitad del siglo XVI. El avance de los hielos supondría una acentuación de las condiciones de frío durante esa centuria, lo que puede ser corroborado por los datos de los navios que consignan temperaturas estivales frías y muy frías en la vertiente pacífica. Estos datos coincidirían con los resultados de $R$. Villalba en cuanto a que el intervalo 1520 a 1670 fue uno de los más fríos de la Pequeña Edad Glaciar.
\end{abstract}

\section{Introducción}

Son escasos los antecedentes sobre estudios paleoclimáticos en el extremo sur de Sudamérica que han utilizado información proveniente de fuentes históricas españolas. Mateo Martinic, en sus trabajos históricogeográficos sobre la región, se ha ocupado del tema, pero sin estudiar sistemáticamente los eventos climáticos del pasado. ${ }^{1}$ Otros autores han usado descripciones de ingleses y españoles sobre glaciares patagónicos en los

1 Martinic Beros, Mateo: Crónica de las Tierras del Sur del Canal Beagle, Buenos Aires, 1973. Del mismo autor también se puede consultar: Magallanes. Síntesis de Tierra y Gentes, Buenos Aires, 1972. 
siglos XVIII y XIX para reforzar o ejemplificar resultados de estudios glaciológicos sobre el terreno. ${ }^{2}$

El objetivo de este trabajo es lograr una aproximación al clima y a los fenómenos de glaciación ocurridos en esa región $\left(50^{\circ} \mathrm{S}\right.$ hasta las costas del Estrecho de Magallanes a los $54^{\circ} \mathrm{S}$ ) durante el siglo XVI y parte del XVII a través de datos históricos. Se complementan los resultados obtenidos por investigadores de otras disciplinas paleoclimáticas en el área austral del continente.

Es aceptado que el siglo XVI, objeto del presente análisis, se inscribe dentro del período de acentuación de las condiciones climáticas extremas desarrollado en las últimas centurias y cuya culminación se produce a mediados del siglo XIX: la Pequeña Edad Glaciar (PEG). Este fenómeno está considerado como uno de los eventos climáticos más significativos ocurridos durante los últimos mil años. Si bien las evidencias son más contundentes en el Hemisferio Norte -Europa y el Atlántico Norte- ${ }^{3}$ su existencia, con algunos desfases cronólógicos, también ha sido verificada en Sudamérica a través de estudios glaciológicos. ${ }^{4}$ Rothlisberger,${ }^{5}$ de acuerdo a una compilación de fechados de radiocarbono realizados en los glaciares del Sur de la Patagonia, señala lapsos sin avances glaciares entre 1440-1550, 1700-1800 y 1850-1900. Se desprende de esta periodificación que los intervalos $1550-1700$ y $1800-1850$ se podrían caracterizar como períodos de avance $\mathrm{o}$, al menos, de no retroceso de glaciares.

Los trabajos sobre anillos de árboles realizados por Villalba ${ }^{6}$ en el Valle del Río Alerce (Pcia. de Río Negro-Argentina) con Fitzroya cupressoides le permitieron reconstruir las temperaturas de verano de los últimos 1000 años, detectando tres episodios donde se alternan altas y bajas temperaturas. Señala como contemporáneo con la Pequeña Edad Glaciar el período entre 1270 y 1670, en el cual prevalecieron condiciones de menor

2 Mercer, J.: "Holocene Glacier Variations in Southern South America. Holocene Glaciers", Striae, N. ${ }^{\circ}$ 18. Uppsala, 1982, págs. 35-40.

3 Confr. Lamb, H.H.: Climate, Present, Past and Future, Vol. 2. London, 1977; Le Roy Ladurie, E.: Historia del clima desde el año mil. México, 1990; Pfister, Ch.: "Snow cover, snowlines and glaciers in Central Europa since the 16th century". Reprinted from: The climatic Scenes, M.J. Tooley and G.M. Sheail (ed.), London, 1985, págs. 154-174.

4 Mercer, J.: "Glacier Variations in Southern Patagonia". Geography Review, N. o 55, 1965, págs. 390-413; Grove, Jean: The little Ice Age. London and New York, 1988; Hastenrath, S.: The glaciation of the Ecuadorian Andes, Rotterdam, 1981.

5 Rothlisberger, F.: 10000 Jahre Gletchergeschichte der Erde. Salzburg, 1986.

6 Villalba, R.: "Tree-Rings and glacial evidence for the Medieval Warm Epoch and the Little Ice Age in Southern South America". Climatic Change, N. ${ }^{\circ} 30,1994$, págs. 1-15. 
temperatura estival y menor precipitación invernal. El intervalo más frío se produjo entre 1520 y 1670, coincidentemente con los primeros relatos sobre el paso de navíos españoles a través del Estrecho de Magallanes.

En el extremo sur sudamericano habría coincidido ese último período de agudización de las condiciones extremas (1520-1670) con uno de los momentos señalados como de no retroceso de glaciares en la Patagonia: 1550-1700. Es nuestro interés en este trabajo verificar si las fuentes históricas corroboran las conclusiones de los autores citados.

\section{Descripción de la información}

\section{Fuentes históricas utilizadas}

La información climática en América del Sur proveniente de la etapa colonial presenta desfases temporales, vinculados al momento de la exploración, conquista y colonización de cada región en particular. A fines del siglo XV, los españoles pusieron pie en las Antillas y en medio siglo de rápido y constante avance, dominaron buena parte del Nuevo Mundo. La región austral sudamericana es una de las áreas que presenta la información más temprana, provista por Magallanes al cruzar el Estrecho que separa el continente de la isla de Tierra del Fuego en 1520.

Una vez afianzada la conquista, el tráfico entre España y las colonias americanas se realizaba mediante convoyes de galeones que llegaban a Cartagena de Indias y a Portobelo. Desde esta ciudades, se comunicaban por tierra, a través del Istmo de Panamá, con las costas del Pacífico. A partir de la segunda mitad del XVI se establece el tráfico anual del Galeón de Manila, que unía comercialmente México con Filipinas.?

Esto no hubiera sido posible sin las primeras expediciones que se arriesgaron a cruzar el Estrecho de Magallanes en busca de la tierra de la especiería. Estas expediciones eran armadas por la Corona Española o por particulares interesados en el comercio con el lejano oriente. Se trataba fundamentalmente de naves llamadas genéricamente en esa época "navíos mancos y pesados". De acuerdo con Chaves, en su obra Quatri partibus: Espejo de Navegantes, las más corrientes eran las naos de 240 toneladas "por ser más común su uso en toda la navegación". ${ }^{8}$ Las flotas estaban com-

7 Morales Padrón, F.: Historia del Descubrimiento y Conquista de América. Madrid, 1973.

8 Castañeda, Delgado, P.; M. Cuesta y P. Hernández: Alonso de Chaves (1537) Quatri Partitu en Cosmografía practica y por otro nombre llamado Espejo de Navegantes. Madrid, 1983. pág. 210. 
puestas por varias naos, a cuyo mando la Corona, los armadores, comerciantes o banqueros colocaban un capitán general encargado de la buena marcha de la expedición. ${ }^{9}$ siendo cada nao comandada por un capitán o maestre. El piloto gobernaba la navegación de la nao y guiaba las rutas que debía seguir, mediante el uso de la carta de navegación, agujas de marear, relojes de arena, compases, sondas, astrolabios y cuadrantes de madera. ${ }^{10}$

\section{Los diarios o relaciones de navegación}

Para realizar este trabajo se utilizaron los diarios de navegación de los primeros marinos españoles que pasaron por el Estrecho, algunos publicados y otros aún inéditos. Estos últimos se recopilaron en su mayor parte en el Archivo del Museo de la Marina (Madrid) y en el Archivo General de Indias. Se denominaban Diarios o Relaciones de Navegación por tratarse de una segunda redacción, más cuidadosa y completa, de los cuadernos de bitácora.

Se seleccionaron los diarios de navegación de las siete expediciones de origen hispano más representativas entre las que cruzaron el Estrecho entre 1520 y 1619 . Se descartaron por contar con escasos datos climáticos o muy generales los de Juan de Mori de la expedición de Ximón de Alcazaba ${ }^{11}$ y de Juan Ladrillero. ${ }^{12}$ En algunos casos se ha contado con los diarios correspondientes a dos y hasta tres navíos de la misma flota, lo que sirvió para comparar y validar la información. En la expedición de Magallanes (1520), escribieron Francisco de Albo ${ }^{13}$ y Antonio Pigafetta; ${ }^{14}$ en la armada de Frey García Jofré de Loaysa (1526-27) hicieron la relación diaria éste mismo, Andrés de Urdaneta ${ }^{15}$ y Juan de Areyzaga; ${ }^{16}$ la expedición de Francisco de Ulloa (1553-54) fue registrada por el capitán

9 Randier, J.: Hommes et navires au Cap Horn. Paris, 1960.

10 Castañeda, Cuesta y Hernández: Alonso de Chaves... Espejo de Navegantes.

11 "Relación de Juan Mori de la Expedición de Ximon de Alcazaba. 1535”. Pastells, Pablo: El Descubrimiento del Estrecho de Magallanes en conmemoración del IV Centenario del Descubrimiento de América, Madrid, 1910, pág. 263.

12 Ladrillero, J.: "Descripción de la Costa del Mar Océano desde el sur de Valdivia hasta el Estrecho de Magallanes inclusive", 1558. Ibídem, Doc. N. ${ }^{\circ} 15$, págs. 338-367.

13 "Diario o derrotero del viaje de Magallanes desde el Cabo de San Agustín hasta el regreso a España de la Nao Victoria, escrito por Francisco Albo, 1520". Fernández de Navarrete, L.: Colección de los viajes y descubrimientos que hicieron por mar los españoles, T. IV, Madrid, 1837.

14 Pigafetta, Antonio: Primer viaje en torno del globo, 1520. Buenos Aires, 1954.

15 Archivo del Museo Naval de Madrid, Manuscrito 197, folio 67. "Relación de la Armada de Loaysa por Andrés de Urdaneta". 1525.

16 Ibídem, folio 9. "Relación diaria que dio Juan de Areyzaga, clérigo natural de Guipúzcoa, sobre la navegación que hizo la Armada de S.M. de que iba por Capitán el Comendador Loaysa hasta la desembocadura del Estrecho de Magallanes el año 1525". 
Hernando Gallego ${ }^{17}$ y Gerónimo de Vivar; ${ }^{18}$ la expedición de Juan Ladri1lero ${ }^{19}$ (1557-58) por el capitán Cortés de Ojea; ${ }^{20}$ en la expedición de Pedro Sarmiento de Gamboa (1578-80) escribieron, además del capitán general, ${ }^{21}$ los pilotos Antón Pablos y Hernando Lameros y la relación diaria de la armada de los Hermanos Nodal (1618-19) fue escrita por el capitán general Nodal ${ }^{22}$ y por el cosmógrafo Diego Ramírez de Arellano. ${ }^{23}$

Se cuenta solamente con un relato de cada viaje proveniente de la Armada del Obispo de Plasencia ${ }^{24}(1539-40)$ y de las de Sarmiento de Gamboa de $1581-82$ y $1583-84 . .^{25}$

Si bien las flotas en su mayoría habían partido de España, dos de ellas, las de Ulloa y Ladrillero, salieron del Puerto de Valdivia en la costa chilena $\left(39^{\circ} 45^{\prime} \mathrm{S}\right)$ y la primera expedición de Sarmiento de Gamboa del Puerto del Callao en Perú. Tenían por misión "descubrir y explorar el Estrecho de Magallanes".

\section{Características de los datos proporcionados por los diarios}

La base de datos climáticos de Tierra del Fuego para el período 15201618 cuenta con 753 datos, correspondientes a diarios de navegación y relatos de españoles, ingleses y holandeses.

17 "Declaración del Estrecho de Magallanes. Expedición de Francisco de Ulloa. Relación de Hernando Gallego. 1553". Barros, J.M.: "Expedición al Estrecho de Magallanes en 1553". ANS. INST. PAT. Punta Arenas (Chile), N. ${ }^{\circ} 12,1981$, págs. 31-40.

18 Bibar, Gerónimo de (1553-58): Crónica y Relación copiosa y verdadera de los Reynos de Chile. Edición facsimilar del Fondo Histórico y Bibliográfico J. T. Medina, Santiago de Chile, 1966.

19 Ladrillero, J.: "Descripción de la Costa del Mar Océano...".

20 "Relación diaria del Capitán Francisco Cortés de Ojea, Capitán del Bergantín San Salvador, escrita por el escribano Miguel de Goyzueta", 1557-58. En: Gay, Claudio: Historia Física y Política de Chile. T. II, Documentos sobre la historia, la estadística, la geografía. Imprenta de E. Thunot, París, 1852, págs. 55-97.

21 Sarmiento de Gamboa, Pedro: Viajes al Estrecho de Magallanes. Introducción, transcripción y notas de J. Sarabia Viejo. Madrid, 1988.

22 Biblioteca Nacional, Madrid. Manuscrito N. ${ }^{\circ}$ 19873. "Reconocimiento de los Estrechos de Magallanes y San Vicente mandado hacer por S.M. en el Real Consejo de Indias. Partieron de Lisboa en 27 de setiembre de 1618 y llegaron de vuelta a San Lúcar a 9 de julio de 1619. Cabo de dos carabelas Bartolomé García de Nodal y Capitán Gonzalo de Nodal: Cosmógrafo Diego Ramírez: Piloto Juan Manço", 1619.

23 Ibídem, Manuscrito N. ${ }^{\circ}$ 3019. "Discurso y derrotero del viaje a los Estrechos de Magallanes y Mayre por el Cosmógrafo Diego Ramírez de Arellano", 1618-19.

24 Archivo del Museo Naval de Madrid. Manuscrito 141, doc. 12. "Relación del suceso de la Armada del Obispo de Plasencia que salió de España en el año de 1539 compuesta de cuatro navíos para la especiería por el Estrecho de Magallanes...sacada de una carta escrita a Lázaro Alemán por Cristobal Rayzer", 12 de julio de 1541.

25 Sarmiento de Gamboa, Pedro: Viajes al Estrecho de Magallanes. 
La selección realizada previamente y la necesidad de aplicar técnicas lingüísticas como el análisis de contenido, condujo a considerar solamente las relaciones diarias escritas en español, lo que restringió el número de datos. Se descartaron también los datos sobre la zona del Océano Atlántico situada al sur de la Isla de los Estados.

Se utilizó sólo la información del período primavera-verano, desde octubre a marzo, debido a que prevalecen los datos correspondientes a ese intervalo, descartándose los escasos registros invernales por su mínima representatividad. Así la base quedó reducida a 513 registros.

Las primeras expediciones proveen escasa información meteorológica. Fundamentalmente se consignaba un evento extraordinario o catastrófico que pusiera en peligro la nao y su tripulación y eventualmente alguna otra información de interés relacionada con la navegación. A mediados del siglo XVI se observa mayor minuciosidad en las anotaciones, que se registran diariamente, pero sin horas fijas. En las expediciones de Sarmiento de Gamboa $^{26} \mathrm{y}$ de los Hermanos Noda ${ }^{27}$ ya existe una rutina de observaciones tres veces al día. La gran cantidad de información producida a fines del XVI provoca un marcado desequilibrio entre ésta y la provista por los primeros registros. Esto se ha solucionado trabajando la información en porcentajes.

La estrecha dependencia de los barcos a vela de la intensidad y dirección del viento, de las corrientes marinas y en menor medida de otros acontecimientos climáticos, se ve reflejada en la prioridad otorgada a estos fenómenos en los diarios de navegación. En consecuencia, el viento, el estado del mar y el tiempo presente son los eventos anotados más frecuentemente. Gran importancia se confería a las descripciones del paisaje de ambas costas del Estrecho, incluyendo la presencia de bosques, hielo, nieve y rocas.

\section{Localización de los sitios}

La localización de las observaciones hechas por las naos - especialmente sobre glaciares y témpanos de hielo- presenta algunas dificultades derivadas de la imprecisión de los instrumentos de navegación utilizados durante este período.

El astrolabio y las tablas de declinación del sol permitían determinar con bastante aproximación la latitud a mediodía calculando la altura del

26 Ibídem.

27 Biblioteca Nacional, Madrid. Manuscrito N. ${ }^{\circ}$ 19873. "Reconocimiento de los Estrechos de Magallanes y San Vicente por Bartolomé García de Nodal y Capitán Gonzalo de Nodal”. 
sol. ${ }^{28}$ Conociendo la latitud, las distancias en leguas o en grados recorridas de un punto a otro y los nombres de las localidades que han perdurado hasta el presente, se puede ubicar con cierta seguridad los sitios mencionados en las relaciones de navegación.

La relación legua marina-grados es definida por Alonso de Chaves. ${ }^{29}$ Afirma que cinco grados y cinco séptimos hacen cien leguas según el uso de España, de modo que un grado corresponde a 17 leguas y media. Una legua marina española equivalía en 1587 a cuatro millas o modernamente a $5.5722 / 3$ metros. $^{30}$

El afán de señalar cuidadosamente la latitud y las distancias respondía a la necesidad de confeccionar pormenorizados "derroteros del Estrecho" donde se localizaban puertos naturales, bahías y demás accidentes geográficos de ambas costas a lo largo del pasaje. Toda nao que cruzaba el Estrecho confeccionaba su propio derrotero y mapas acompañantes. Surge de esto un problema: que cada expedición, atribuyéndose el descubrimiento, rebautizaba una buena parte de estos accidentes geográficos. Esto ha provocado confusiones al momento de localizar descripciones y fenómenos.

Estos inconvenientes han sido superados en parte por el acceso a las cartas geográficas realizadas durante el siglo XVI y sobre todo al Mapa Marítimo del Estrecho de Magallanes realizado por el geógrafo Juan de la Cruz Cano y Olmedilla en 1769. ${ }^{31}$ Para confeccionarlo Cano y Olmedilla utilizó toda la información existente sobre el pasaje por el Estrecho derivada de relaciones y memorias de viajes, sobre todo las de Sarmiento de Gamboa. Es de suma utilidad porque consigna los sucesivos nombres asignados por los navegantes españoles y de otras nacionalidades a cada accidente geográfico que "descubrían" (Fig. 1).

\section{Procesamiento de la información}

\section{Obtención de categorías climáticas}

Se derivaron diez categorías climáticas a partir de los propios textos considerados. Para obtener estas variables fueron examinados los diarios en detalle con el fin de determinar un rango completo de información climática.

28 Castañeda, Cuesta y Hernández: Alonso de Chaves... Espejo de Navegantes., pág. 121.

29 Ibídem.

30 Nagy, A. S.: "La legua y la milla de Colón". Cuadernos Colombinos, N. ${ }^{17}$. Valladolid, 1991, págs. 22-41.

31 Archivo General de Indias, Mapas y Planos. Buenos Aires, 239. 
Se acudió a la técnica del análisis de contenido para verificar la estabilidad en el vocabulario referido al clima y los glaciares a lo largo de la centuria. Es destacable en este sentido la consistencia terminológica que presenta el conjunto de registros..$^{32}$ Esta consistencia puede relacionarse con el lugar de origen de los marinos españoles en ese siglo, la mayoría de los cuales provenía del norte de España: País Vasco, Galicia. Esto incidía también en la forma de percibir los fenómenos meteorológicos. Al estar habituados al frío y a la nieve se puede confiar en la certeza de su apreciación cualitativa de los fenómenos.

Al mismo tiempo, desde la perspectiva meteorológica contemporánea se desarrollaron, utilizando el vocabulario técnico correspondiente, las siguientes categorías climáticas:

Precipitación: Se establecieron dos grandes divisiones: lluvia y nieve. Se consignó la apreciación cualitativa de cada fenómeno: intermitentemoderado-abundante.

Tiempo presente: se incluyeron cuatro categorías: sin nubes, seminublado, niebla, tormentoso sin precipitaciones.

Tormentas: Se registró la ocurrencia para determinar su frecuencia y si es posible la apreciación cualitativa del evento.

Temperatura no-instrumental: se desarrollaron cinco categorías con referencias subjetivas: muy cálido, cálido, templado, frío, muy frío.

Estado del mar: calmo-picado-grueso.

Dirección del viento: se registraba mediante la "rosa de los vientos" con sus treinta y dos líneas de compás. En la práctica lo reducían a dieciséis cuadrantes.

Intensidad y tipo de viento: en general no hay una separación neta entre estas dos variables en la documentación. Para la caracterización de la intensidad se utilizó la apreciación del evento: sin viento-suave-regularintenso. Ejemplos de tipo de viento son: "travesía", "frescachón".

Los rangos "precipitación abundante" y "viento intenso" son los que presentan mayor cantidad de equivalencias significativas: 22 y 24 respectivamente, lo que podría indicar un predominio de estos eventos en los viajes analizados. Se incorporó también el avistamiento de icebergs y glaciares y la posición geográfica.

32 Baron, W.: "The reconstruction of eighteenth century temperature records through the use of content analysis". Climatic Change, N. ${ }^{\circ} 4,1982$. 


\section{Asimilación de las expresiones sobre el clima en el siglo XVI a las categorías actuales}

Con el objeto de adecuar las categorías climáticas del siglo XVI al lenguaje actual se estableció y calibró el significado de las expresiones y alusiones del pasado referidas a fenómenos climáticos. Se utilizó para esta tarea el Tesoro de la Lengua Castellana o Española ${ }^{33}$ el ya mencionado Espejo de Navegantes de $1537^{34}$ y el Diccionario Marítimo Español, ${ }^{35}$ con el fin de determinar las equivalencias de significado entre el lenguaje climático del siglo XVI y el actual.

La técnica del análisis de contenido permitió también calificar los eventos de acuerdo a su magnitud, estableciendo un rango entre fenómenos de la misma naturaleza. ${ }^{36}$

En la Tabla se puede observar las categorías climáticas actuales y las palabras, frases o expresiones equivalentes utilizadas en el siglo XVI. Esta labor permitió además asegurar que cada expresión o referencia climática sería consignada siempre dentro de la misma categoría. De las variables determinadas se seleccionaron precipitaciones sólidas y líquidas, temperatura, dirección del viento y ocurrencia de tormentas para analizar con detenimiento en este trabajo. Se estudia especialmente la presencia de témpanos en el Estrecho y las descripciones de los glaciares fueguinos y del sur de la Patagonia chilena como indicadores de bajas temperaturas.

\section{El clima austral en el siglo XVI}

En la actualidad los patrones de precipitación de la Patagonia oriental y occidental están condicionados por la circulación de los vientos del oeste. Sin embargo la cordillera de Los Andes ejerce un fuerte control orográfico en la cantidad de precipitación, ${ }^{37}$ situación que se prolonga hasta nuestra área de estudio (Fig. 2).

33 Cobarrubias Orozco, Sebastián: Tesoro de la lengua castellana o española, 1611. Ed. de Felipe R. Maldonado. Madrid, 1994.

34 Castañeda, Cuesta y Hernández: Alonso de Chaves... Espejo de Navegantes.

35 Diccionario Marítimo Español. Imprenta Real, Madrid, 1831.

36 Baron: "The reconstruction of eighteenth century temperature records...".

37 Endlicher, W.: "Climatological Aspects of Landscape Degradation in Patagonia". Climatology and Air Pollution. Mendoza, 1995, págs. 251-254. 
$\mathrm{Al}$ sur de $50^{\circ} \mathrm{S}$, la vertiente occidental de la cordillera presenta abundantes precipitaciones bien distribuidas a lo largo del año (entre $4000 \mathrm{~mm}$ en Bahía Félix y $2028 \mathrm{~mm}$ en Cabo Rapel). El clima es marítimo, con temperaturas medias en la temporada primavera-verano de $7.5^{\circ} \mathrm{C}$ en Evangelistas $\left(52^{\circ} 24^{\prime} \mathrm{S}\right)$. En este mismo sitio prevalecen los vientos del NW durante todo el año, con excepción de los meses de junio y julio, en que predominan los del SW. ${ }^{38}$

$\mathrm{Al}$ este de los Andes, el clima es continental, alcanzando las temperaturas de primavera-verano un promedio de $9.5^{\circ} \mathrm{C}$ en Punta Arenas. Las precipitaciones disminuyen a casi $200 \mathrm{~mm}$ por año en las planicies. De acuerdo con datos provenientes de los Servicios Meteorológicos de Argentina y Chile ${ }^{39}$ se observa una variación local importante de las lluvias anuales (por ejemplo, $447 \mathrm{~mm}$ en Punta Arenas y $226 \mathrm{~mm}$ en Río Gallegos). En este sector predominan los vientos del Oeste. Endlicher ${ }^{40}$ señala que en Kampenaike $\left(52^{\circ} 41^{\prime} \mathrm{S}, 70^{\circ} 54^{\prime} \mathrm{W}\right)$ predominan los oestes puros en más del $50 \%$.

Sobre la base de las evidentes diferencias climáticas entre ambas vertientes los datos históricos recopilados fueron incluidos en función de su localización geográfica, en la región de clima marítimo o en la región de clima continental. Hemos tomado como límite la divisoria entre bosques y estepas que pasa al sur de la Península de Brunswick.

\section{Temperaturas}

En los diarios de navegación analizados entre 1520 y 1620, se presenta, tanto en la zona de clima marítimo como en la de clima continental, un predominio de bajas temperaturas estivales. En 1520-21; 1539-40; 1553-54 y 1557-58 se reportan exclusivamente temperaturas frías y muy frías (Fig. 3).

Durante el verano $1579-80$ y los siguientes (1582-83 y 1583-84) se verifican cambios en las condiciones térmicas. En la primera temporada hay un apreciable porcentaje de días cálidos y muy cálidos en la vertiente de influencia atlántica: $69.5 \%$. Sarmiento de Gamboa anota el 15 de febrero de 1580 que en el Estrecho a la altura de 53 grados y medio $\left(71^{\circ} \mathrm{LW}\right.$, en las cercanías de la actual Ciudad de Punta Arenas) “..hizo este día y el día antes tanto calor como en Lima por Cuaresma y como en España por

38 Miller, A.: "El clima de Chile. Climates of Central and South America". World Survey of Climatology, N. ${ }^{\circ} 12$, Amsterdam-Oxford-New York, 1976, págs. 113-145.

39 Endlicher, W.: "Climatological Aspects of Landscape Degradation in Patagonia".

40 Ibídem. 
julio". ${ }^{41}$ En la zona occidental también se registran días cálidos pero en menor porcentaje: $10.6 \%$.

En las temporadas subsiguientes (1582-83 y 1583-84)), no hay información sobre el área correspondiente al Pacífico, pues Sarmiento dedicó sus esfuerzos a reconocer los sitios adecuados para fundar dos fuertes en el Estrecho sobre la vertiente de clima continental. En el verano de 1583-84 se procede a la instalación de colonos en las recién fundadas ciudades El Nombre de Jesús y Rey Felipe, situadas la primera a “...treinta leguas del Cabo Vírgenes...” ${ }^{2}$ y la segunda en el sitio ocupado por el actual Puerto Hambre. En la temporada 1582-83, disminuye el porcentaje de días muy cálidos a $6.7 \%$ y no se consignan días cálidos. En la segunda temporada hay un predominio absoluto de días cálidos $83.3 \%$.

Durante la temporada 1618-19 en el Atlántico predominan días fríos y muy fríos aunque con un porcentaje apreciable de días cálidos, 28.6\%. Por el contrario en la vertiente pacífica prevalecen los días muy fríos: $83.3 \%$.

\section{Precipitaciones}

Hasta 1618-19 en la vertiente de influencia atlántica, predominaron los días sin precipitaciones en un rango que oscila entre un 85 y un $100 \%$. Las escasas precipitaciones consignadas se produjeron en forma de lluvia (Fig. 4). En esa última temporada los días sin precipitaciones disminuyeron a $75 \%$.

Esta tendencia se observa también en la vertiente marítima, pero en coincidencia con el patrón climático actual, se verifica un mayor porcentaje de días con precipitaciones en relación al Atlántico, en todas las temporadas analizadas. En 1557-58, hay un $48 \%$ de días con precipitaciones, disminuyendo en $1579-80$ a un $37 \%$.

La temporada estival de 1618-19 muestra un $63.5 \%$ de días con precipitaciones abundantes, que coincide con el incremento ocurrido en el sector oriental.

\section{Vientos}

En las descripciones generales sobre la región los autores de las relaciones realizan una síntesis inconsciente de las observaciones climáticas efectuadas durante la travesía, haciendo una generalización sobre el clima

41 Sarmiento de Gamboa: Viajes al Estrecho de Magallanes, pág. 121.

42 Ibídem, pág. 270. 
del área. Los diarios de navegación en general consignan un predominio de los vientos del SSW, SW y WSW en la época estival, aproximadamente como es en la actualidad.

Solamente dos de los navegantes señalan la importancia de los nortes en el área occidental del Estrecho. Ladrillero en $1557^{43}$ afirma que en el Estrecho desde la boca oeste hasta aproximadamente 30 leguas $(140 \mathrm{~km})$ hacia el este predominaban los nortes en el verano y oestes y sudoestes en el invierno. Lo mismo sostiene Sarmiento de Gamboa en 1579: “...vienta norte, NW y W tempestuosísimo y cuando quiere acabar la tempestad de norte y venir la travesía graniza con gran refriega y hace frío intenso y con el norte hace más templado". ${ }^{44}$

Remitiéndonos al análisis de los años seleccionados, en ambas vertientes, hasta la temporada estival 1553-54 predominan los vientos del cuadrante sur. Se debe aclarar que estos datos hay que tomarlos con precaución, pues se cuenta con muy escasos registros de dirección de viento como para poder realizar una generalización.

En los datos disponibles a partir de 1557-58 y años subsiguientes (1579-80; 1582-83 y 1583-84) se acentúa la ocurrencia de los vientos del cuadrante norte y NE, cuyo porcentaje oscila alrededor del $40 \%$ en el sector occidental y alcanzando en el oriental un $47.6 \%$ en el verano $1583-84$ (Fig. 5). En 1618-19 nuevamente hay un predominio de los vientos del sur y SW en ambos sectores: $50 \%$ en la zona pacífica y $60.9 \%$ en la atlántica.

\section{Glaciares y témpanos en el siglo XVI}

Los fenómenos anómalos observados en los años 1557-58 y 1579-80 - predominio de vientos del cuadrante norte, presencia de días extremadamente cálidos para la región y precipitaciones abundantes- pueden haber favorecido el desprendimiento de los bloques de hielo que encontraron los marinos en el área occidental del Estrecho en la segunda mitad del siglo XVI.

A pesar de las pormenorizadas descripciones registradas desde 1520 hasta 1557, los diarios de navegación analizados no mencionan la presencia de témpanos durante el cruce del Estrecho. Este fenómeno no hubiera pasado desapercibido para los tripulantes de las naos de principios del XVI

43 Ladrillero, J.: "Descripción de la Costa del Mar Océano..." .

44 Sarmiento de Gamboa: Viajes al Estrecho de Magallanes., pág. 58. 
dada su potencial peligrosidad para la navegación y por la novedad que les habría significado esas enormes moles de hielo flotando en el mar.

Para reafirmar esta apreciación se revisaron también otros relatos diarios de navegantes que hubieran pasado por el Estrecho de Magallanes durante el período estudiado, como James Weddell en $1523^{45}$ y Juan Mori (de la expedición de Ximón de Alcazaba) en 1535, ${ }^{46}$ con los mismos resultados negativos.

En 1557, la expedición exploratoria al mando del capitán Juan Ladrillero, enviada por el gobernador García Hurtado de Mendoza desde Valdivia, registró la presencia de grandes superficies englazadas en los fiordos chilenos desde los $51^{\circ}$ hasta el Estrecho. La información acerca de grandes témpanos flotando en los canales y bahías recorridas sugiere cambios en la condición de los glaciares en relación a las descripciones de la expedición de Ulloa en 1553, quien no registra ese fenómeno.

La primera mención sobre la presencia de "bancas de nieve" procede del capitán de una de las naves de la expedición, Cortés Ojea, quien creyendo entrar al Estrecho se introduce treinta leguas $(150 \mathrm{~km})$ por el canal de la Concepción (5050’S):

“... en este paraje hallamos muchos pedazos e islillas de nieve que iban nadando sobre el agua las cuales pareció salían de un abra e valle nevado que está al SE deste dho. Puerto Bonifacio e surtos que fuimos bien cerca de tierra en treinta brazas dimos proa en tierra en la cual estaba zabordada una isla de nieve tan dura como peña, que los remos no la podían romper". ${ }^{47}$

Buscando el origen del hielo, navegaron entre veinte y veinticinco leguas hacia el interior del fiordo hasta que encontraron una gran bahía de la cual salía "mucha nieve nadando", encontrando el imponente frente del glaciar llegando hasta el mar : “...el camino le halló cerrado de nieve e llegándonos más cerca lo vimos desde el navío estar cerrado de nieve de cerro a cerro; esta nieve era tan alta que enchía hasta la mitad de los cerros... hasta que vimos se remataba en unos tres balcones o cerros altísimos e cuajados de nieve hasta la lengua del agua de los cuales descendía mucha nieve que cuajaba la dicha bahía...". ${ }^{48}$

45 Randier: Hommes et navires au Cap Horn.

46 "Relación de Juan Mori de la Expedición de Ximon de Alcazaba. 1535". Pastells, Pablo: El Descubrimiento del Estrecho de Magallanes...

47 “Relación diaria del Capitán Francisco Cortés de Ojea...” . Gay: Historia Física y Política de Chile, pág. 62.

48 Ibídem, pág. 64. 
Es indudable que, de acuerdo a la latitud, Cortés Ojea se introdujo por el Estrecho de la Concepción y luego por Canal Ancho, hasta llegar a la lengua de uno de los ventisqueros que forman el campo de glaciares Dr. Brüggen.

Ladrillero, ${ }^{49}$ al mando de otra embarcación, observa el mismo fenómeno donde remata el seno Eyre $\left(49^{\circ} \mathrm{S}\right)$ :

“... donde se acaba entre unas islas nevadas donde hallamos tantas islas de nieve que había algunas que tenían siete estados de alto y del tamaño de un solar y otras menores y más pequeñas que no podíamos pasar aunque el brazo tenía legua y media de ancho y hallándole cerrado dimos la vuelta". ${ }^{50}$ (Siete estados son 1400 metros: 1 estado=200 m).

Mercer ${ }^{51}$ confirma que sobre el lado oeste del icefield de Brüggen (o Pío XI) actualmente se desprenden témpanos de los glaciares dentro del seno Eyre, los cuales entran desde el costado a corta distancia de la cabeza del fiordo (lat. $49^{\circ} 10^{\prime} \mathrm{S}$ y long. $73^{\circ} 58^{\prime} \mathrm{W}$ ).

En el extremo austral, sobre todo en el Estrecho de Magallanes, Ladrillero también encontró témpanos, aunque es más difícil ubicar los sitios que describe. En general alerta a los navegantes sobre las enormes moles de hielo que se desprenden de los glaciares de la cordillera de la porción occidental del Estrecho desde la entrada hasta los 54, fenómeno que describe minuciosamente:

“... si vieren sierras nevadas que caygan sobre el canal por donde fueren que se aparten dellas porque hay en muchas partes donde cae tanta nieve que las tierras tienen sobre sí cinco y seis y siete y ocho y diez líneas de nieve ...y según parece debe estar recogida de muchos tiempos y cuando la sierra está muy cargada della quiebra la nieve y viene rodando haciéndose pedazos a cien estados y doscientos y trezientos y mill...y viene con gran ruido a manera de truenos por la sierra abajo y da en el brazo o canal gran multitud della en pedazos como naos como casas y casi tamaños como solares y menores y de seis y de siete y de ocho estados della en el agua y son tan duros como una peña...y en legua y media de brazo no podiamos pasar con un bergantín sin topar con aquellos pedazos [que] andaban encima del agua como islas que algunas tenían tres y cuatro estados debajo del agua y otros tantos encima della y esto es apartados del mar y de las bahías por los canales que dellas se apartan la tierra adentro hacia la cordillera...". ${ }^{52}$

Este fenómeno es observado por Ladrillero en la costa norte, entre la boca del estrecho y el Seno Otway $\left(53^{\circ} \mathrm{S}\right)$, trayecto que estima en 35 leguas

\footnotetext{
49 Ladrillero, J.: "Descripción de la Costa del Mar Océano...”, pág. 345.

50 Ibídem.

51 Mercer, J.: Southern Hemisphere Glacier Atlas. New York, 1967.

52 Ladrillero, J.: “Descripción de la Costa del Mar Océano...”, pág. 366.
} 
$(175 \mathrm{~km})$. Los glaciares que menciona podrían ser los ubicados en la mitad oeste de la Isla Riesco que presenta muchos picos y grupos montañosos cubiertos de hielo. En el mapa de Cano y Olmedilla está localizada esa zona como "Puerto de la Playa Parda", donde se consigna la presencia de "mucha nieve".

Actualmente, un pequeño icefield se encuentra sobre el Cerro Ladrillero $(1665 \mathrm{~m})$ pero la desembocadura de los glaciares ha retrocedido levemente en épocas recientes. ${ }^{53}$ Se observa además un icefield ubicado cerca de los $52^{\circ} 50^{\prime} \mathrm{S}, 73^{\circ} 10^{\prime} \mathrm{W}$ que se extiende sobre una superficie de 20 por $10 \mathrm{~km}$ que puede haber sido uno de los glaciares descritos por el navegante. ${ }^{54}$

En 1579-80 Sarmiento de Gamboa observa el mismo fenómeno que Ladrillero en este área el 8 de febrero cuando pasa por la Isla de la Cruz (Fig. 6), situada al SE de la Península de Córdoba de acuerdo al mapa de Cano y Olmedilla (podría ser la actual Isla Carlos III):

"Allí se vieron grandes pedazos de nieve andar sobreaguados por la mar, que salen de las islas nevadas que están al sur de esta Isla de la Cruz [a] tres leguas, y las tormentas del viento despedazan la nieve y la echan y sacan a la mar". ${ }^{5}$

Los témpanos a los que se refiere pueden provenir de los glaciares de la Isla Santa Inés, situados, como afirma Sarmiento, aproximadamente a $15 \mathrm{~km}$ o tres leguas de la Isla de la Cruz hacia el sur. Los glaciares de la Isla de Santa Inés son los menos conocidos de Sudamérica de acuerdo con Mercer. ${ }^{56}$ Se sabe sin embargo que un campo de hielo cubre la mayor parte del sudeste de la isla. El Monte Wharton $(1317 \mathrm{~m})$ en el norte presenta glaciares deslizándose sobre ambos flancos, que son los que pudo haber visto Sarmiento de Gamboa.

Navegando hacia el sureste:

“...está un monte muy alto agudo delante de unas sierras nevadas. Este monte es el que llaman las relaciones antiguas la Campana de Roldán. Toda esta bahía de la Campana es cercada de sierras altas y nevadas ...Aquí son las islas nevadas que dicen las relaciones viejas .... la hora que esto escribo, hace calor, estío y calma, sabe muy bien la agua fría con estar cercados de sierras nevadas y balsas de nieve por la mar en 53 grados y dos tercios, donde en muchos meses no suele verse el sol...". ${ }^{57}$

53 Mercer: Southern Hemisphere Glacier Atlas.

54 Ibídem.

55 Sarmiento de Gamboa: Viajes al Estrecho de Magallanes.

56 Mercer: Southern Hemisphere Glacier Atlas.

57 Sarmiento de Gamboa: Viajes al Estrecho de Magallanes, pág. 112. 
Creemos que en este caso Sarmiento se refiere a la Isla Clarence, cuya parte alta, donde sobresale el Cerro Campana, soporta muchos circos glaciarios que en el presente parecen haber sufrido un retroceso moderado. ${ }^{58}$ Cano y Olmedilla marca con exactitud ambas "islas nevadas" y el cerro Campana de Roldán, distinguiéndolas netamente de la "Cordillera de mucha nieve" que es sin lugar a dudas la cordillera de Darwin.

Llama la atención en estas observaciones del siglo XVI la magnitud de los glaciares de estas "islas nevadas", Santa Inés e Isla Clarence, cuyas lenguas llegaban hasta el mar, desprendiendo grandes bloques de hielo.

Con posterioridad a estos avistamientos no se registran más referencias a témpanos procedentes de los glaciares del oeste del Estrecho hasta el fin del período estudiado. Ramírez de Arellano, autor de la última relación analizada, solo consigna montañas de nieve en la costa norte, en el Puerto de San Joseph (Península de Brunswick ?), “...tiene al norte unos montes muy altos y llenos de árboles y nieve y un arrecife de árboles entre el puerto y la ensenada....". ${ }^{59}$

Tampoco se encontró ninguna referencia al tema en los diarios de Thomas Cavendish que pasó por el Estrecho en 1587, de Jacobo Maher en $1599^{60}$ y de J. Le Mayre y G. Scouten en $1619 .{ }^{61}$

\section{Discusión y conclusiones}

Los avistamientos de témpanos desprendidos de glaciares en el Estrecho y en el sur de la Patagonia chilena se producen dentro del siglo XVI en los años 1557-58 y 1579-80. Estos eventos poco frecuentes podrían haberse originado en un considerable aumento del volumen de hielo en el intervalo previo a estos años y el consecuente avance de los glaciares, cuyas lenguas alcanzaron el mar. Los desprendimientos del glaciar Brüggen son propios de su comportamiento aún en la actualidad, de modo que su condición de indicador climático es relativa.

58 Mercer: Southern Hemisphere Glacier Atlas.

59 Biblioteca Nacional, Madrid. Manuscrito 3019. "Discurso y derrotero del viaje a los Estrechos de Magallanes y Mayre por el Cosmógrafo Diego Ramírez de Arellano”, 1618-19.

60 Randier: Hommes et navires au Cap Horn.

61 Archivo del Museo Naval de Madrid, Manuscrito 142.”Viaje que hicieron J. Le Mayre y Guillermo Scouten...a la parte austral del Estrecho de Magallanes. Año 1619. Relación diaria que imprimió en Amsterdam Pedro Xeno en 1622”, pág. 324. 
Tiene mayor relevancia la constatación, en el Estrecho de Magallanes, de la presencia de témpanos fuera del área englazada de la Cordillera de Darwin, especialmente en sitios donde actualmente no se verifica ese fenómeno: en la Isla Riesco y en las Islas Santa Inés y Clarence, "islas nevadas" para los navegantes españoles.

El avance de los hielos supondría una acentuación de las condiciones de frío durante esa centuria, lo que puede ser corroborado por los datos de los navíos que consignan temperaturas estivales frías y muy frías en la vertiente pacífica. Estos datos coincidirían con los resultados de Villalba en cuanto a que el intervalo que se extiende entre 1520 y 1670 fue uno de los más fríos de la Pequeña Edad Glaciar.

La temporada 1579-80 escapa a la caracterización general de este intervalo frío, pues, pese a que predominan los días con muy bajas temperaturas, también se registran días cálidos y muy cálidos (10.6\%). Además en esa primavera-verano alcanzaron mayor relevancia los vientos del primer cuadrante, $\mathrm{N}$ y NE. Este hecho puede haber contribuido al desprendimiento de grandes masas de hielo de los glaciares del Estrecho, luego de un avance y aumento de volumen considerables en los años fríos anteriores. Aunque en el período estival 1557-58 no se verificó un aumento de las temperaturas, se incrementó el porcentaje de los vientos más cálidos del cuadrante norte, que pudieron haber contribuido, junto con las lluvias de ese año, al desprendimiento de bloques de hielo glaciar.

De acuerdo con Quinn, ${ }^{62}$ justamente en los años 1578 y 1579 aparece por primera vez en los registros escritos - categorizado como de extrema severidad- el fenómeno conocido como El Niño-Oscilación Sur (ENSO). Este evento, cuya manifestación más conocida se produce algunos años en la costa del Perú en la época navideña, tiene repercusiones climáticas a nivel planetario. No debería descartarse una relación entre la ocurrencia de ese fenómeno y el período anómalo detectado en Tierra del Fuego en esos mismos años. Se explicaría quizás entonces la decisión de Sarmiento de Gamboa de fundar dos colonias en la costa norte de Tierra del Fuego, llevado por la equivocada impresión causada por la suave e inusual temperatura de ese verano.

62 Quinn, W.H. and V.T. Neal: "The historical record of El Niño events". Climate since A.D. 1500. Ed. R. Bradley and P. Jones. London and New York, 1992, págs. 623-648. 


\title{
Apéndice
}

\author{
TABLA DE EQUIVALENCIAS SIGNIFICATIVAS
}

\section{CATEGORÍA: LLUVIA}

\begin{tabular}{|c|c|c|}
\hline \multicolumn{3}{|c|}{ Descriptor } \\
\hline Intermitente & Moderada & Abundante \\
\hline $\begin{array}{l}\text { aguacerillos de agua } \\
\text { y nieve } \\
\text { Tiempo inconstante }\end{array}$ & $\begin{array}{l}\text { llovió todo el día } \\
\text { lluvia } \\
\text { chubasco de viento y lluvia } \\
\text { tiempo oscuro y lluvioso } \\
\text { chubascos violentos } \\
\text { agua del cielo } \\
\text { agua menuda, espesa } \\
\text { mal tiempo } \\
\text { nos llovió poco } \\
\text { surco de agua y cerrazón }\end{array}$ & $\begin{array}{l}\text { Temporal de viento y agua } \\
\text { Muchos aguaceros } \\
\text { Mucha agua } \\
\text { Mucha agua y granizo } \\
\text { Mucha agua, granizo } \\
\text { y nieve } \\
\text { Tormenta } \\
\text { Duros temporales } \\
\text { Llueve mucho } \\
\text { Fue creciendo la tormenta } \\
\text { Agua con tanta fuerza } \\
\text { Recia tormenta } \\
\text { Tormentas fuertes y lluvias } \\
\text { Grande viento y tormenta } \\
\text { Tormentas fuertes y lluvias } \\
\text { Fuerte temporal y varios } \\
\text { aguaceros } \\
\text { Temporal de rayos, truenos, } \\
\text { relámpagos y agua } \\
\text { Grandes temporales } \\
\text { Mayores tormentas } \\
\text { y peligros } \\
\text { Recios aguaceros } \\
\text { Días malos y aguaceros } \\
\text { Recios tiempos de nieves } \\
\text { y aguaceros } \\
\text { Frescachón con tiempo } \\
\text { muy nebuloso } \\
\text { y abundantes lluvias }\end{array}$ \\
\hline
\end{tabular}




\section{CATEGORÍA: VIENTO}

\section{Descriptor}

\begin{tabular}{|c|c|c|c|}
\hline Sin viento & Suave & Regular & Intenso \\
\hline $\begin{array}{l}\text { Calma } \\
\text { extraordinaria } \\
\text { calmo } \\
\text { cesó el viento } \\
\text { noche serena } \\
\text { falta de viento }\end{array}$ & $\begin{array}{l}\text { bonancible } \\
\text { viento bonanza } \\
\text { vientos calmosos } \\
\text { poco viento } \\
\text { viento escaso } \\
\text { no hacía tiempo } \\
\quad \text { para partir } \\
\text { vientos blandos } \\
\text { abonanzó } \\
\text { bonanza especial }\end{array}$ & $\begin{array}{l}\text { Vientos naturales } \\
\text { ventó } \\
\text { vientos variables } \\
\text { ventando } \\
\text { buen viento } \\
\text { las refriegas de } \\
\text { viento no nos } \\
\text { fatigaron } \\
\text { vientos más } \\
\text { favorables } \\
\text { vientos moderados } \\
\text { el tiempo moderó } \\
\text { muy ventoso } \\
\text { próspero viento }\end{array}$ & $\begin{array}{l}\text { muchas } \\
\text { tempestades } \\
\text { viento } \\
\text { tempestuosísimo } \\
\text { gran refriega } \\
\text { tempestad de viento } \\
\text { y agua } \\
\text { gran tempestad de } \\
\text { agua y viento } \\
\text { viento a refriegas } \\
\text { vientos fuertes } \\
\text { viento furioso } \\
\text { aire recio } \\
\text { borrascas } \\
\text { tanto viento y mar } \\
\text { y refriegas } \\
\text { y travesía } \\
\text { tormentas de viento } \\
\text { ventó tan recio } \\
\text { viento violento } \\
\text { tiempo recio con } \\
\text { tanta pujanza } \\
\text { grande viento } \\
\text { recreció el viento } \\
\text { terribilidad y } \\
\text { tempestuosidad } \\
\text { de los tiempos } \\
\text { fortísimo viento } \\
\text { rebolones de } \\
\text { viento } \\
\text { vientos duros } \\
\text { vientos muy } \\
\text { soberbios } \\
\text { viento de ruin } \\
\text { semblante } \\
\text { refriegas infernales } \\
\text { recias refriegas }\end{array}$ \\
\hline
\end{tabular}




\section{CATEGORÍA: NIEVE Y GRANIZO (GRAUPEL)}

\section{Descriptor}

Moderada
Aguaceros de agua, envueltos en nieve
y granizo
Bonanza con lluvia, nieve y mucho frío
Cargó mucho viento, nieve y mal tiempo
Frío y nieve
Granizó y llovió muy bien
Mucha mar, aguaceros y granizo

Abundante

Mucha agua y granizo y nieve

Nevó muchísimo

Grandes aguaceros de nieve

Grandes refriegas de viento, nieve y granizo

Aguaceros de granizo

Granizó muchísimo

Temporal de granizo tan grueso

Granizo en tanta copia que cubrió el combés

\section{CATEGORÍA: TEMPERATURA}

Descriptor

\begin{tabular}{llll} 
Muy cálido-cálido & Templado & Frío & Muy frío \\
\hline sol caluroso & templado & poco verano & mucho frío \\
mucho calor & buen temple & frío seco & frío intenso \\
días de calor & tierra templada & & gran frío \\
tanto calor como & & muchas heladas \\
$\quad$ en Lima por & & tiempo muy frío \\
$\quad$ cuaresma & & tierra fría y nevada \\
caluroso & & padeciendo frío \\
calma y calor & & muy gran frío \\
tiempos calurosos & &
\end{tabular}




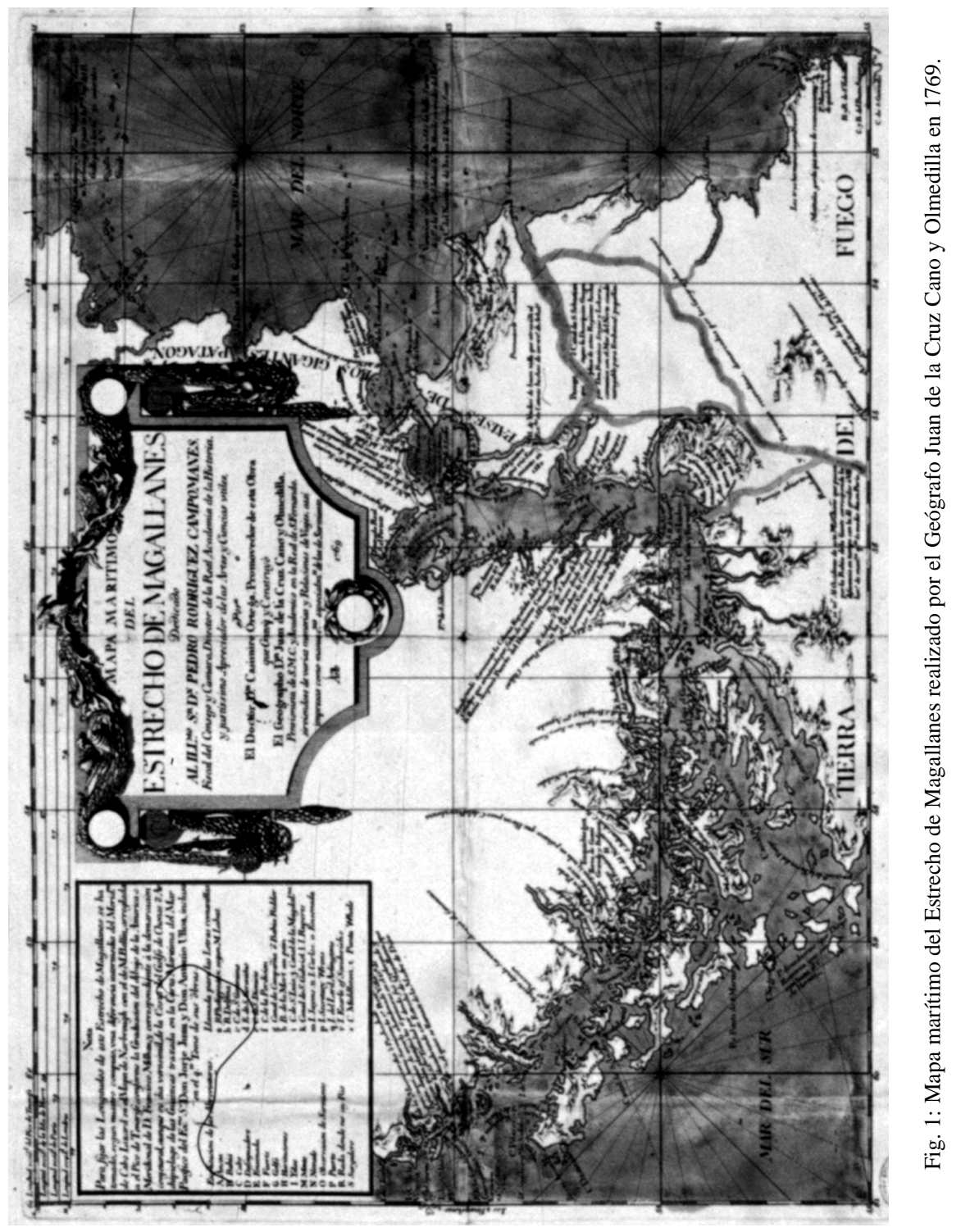




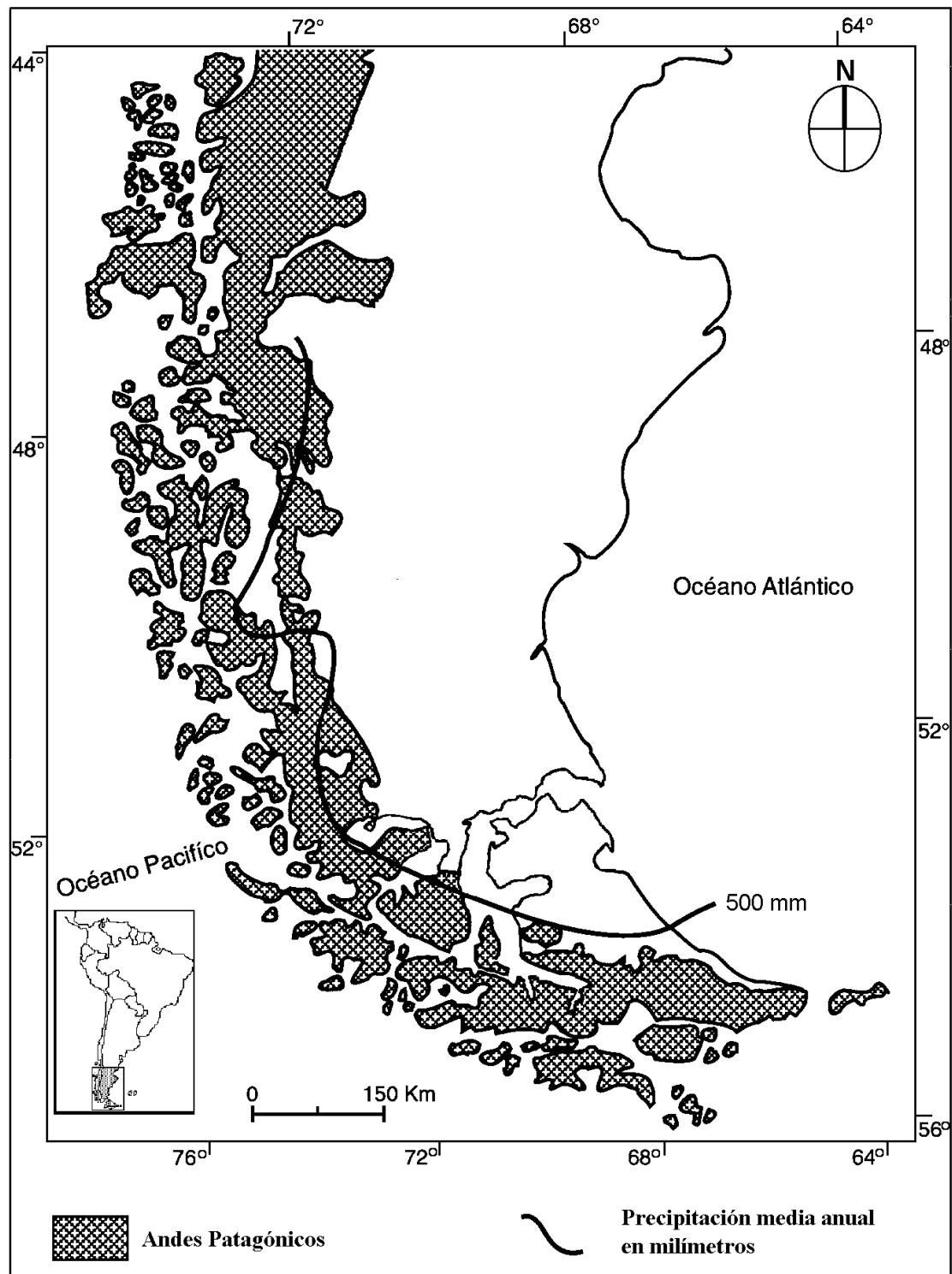

Fig. 2: Vertiente oriental y occidental del Estrecho de Magallanes e Isohieta de $500 \mathrm{~mm}$. 


\section{VERTIENTE ORIENTAL}

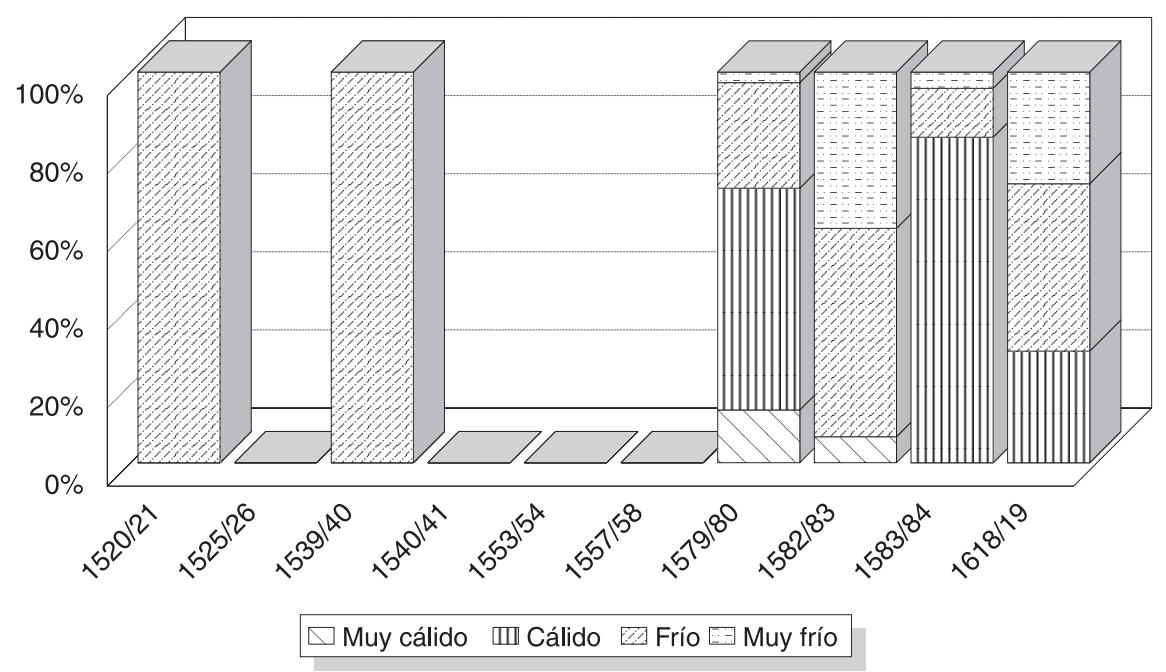

\section{VERTIENTE OCCIDENTAL}

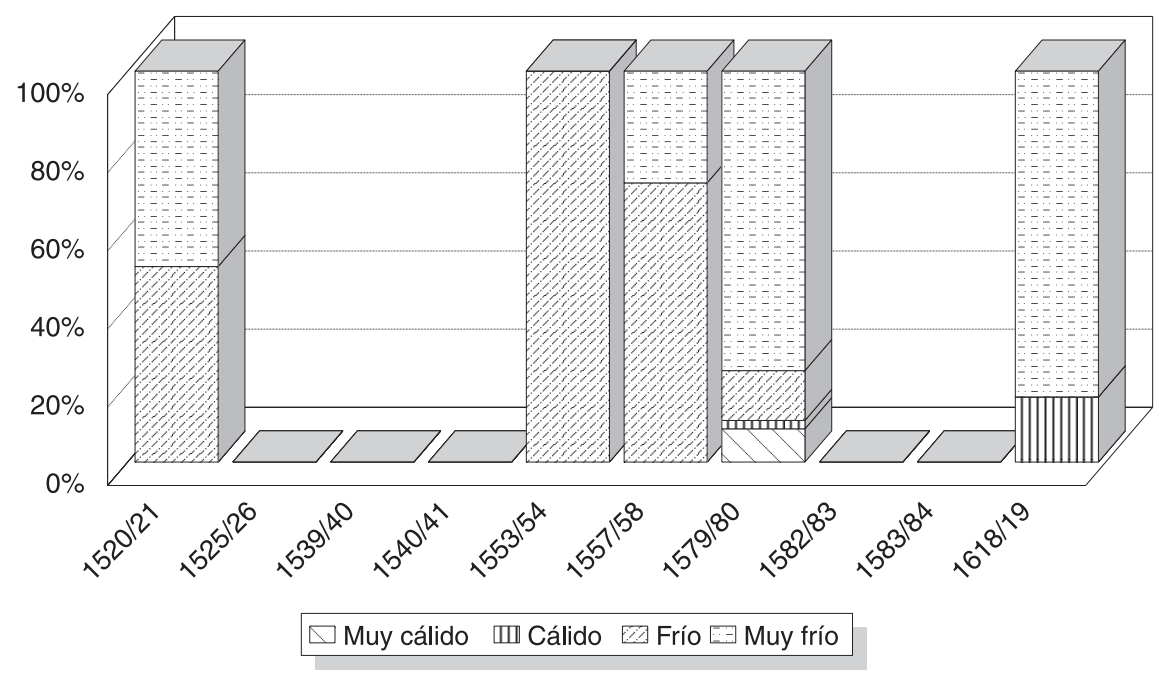

Fig. 3: Temperatura Cualitativa en la zona del Estrecho de Magallanes en el siglo XVI (en porcentajes). 


\section{VERTIENTE ORIENTAL}

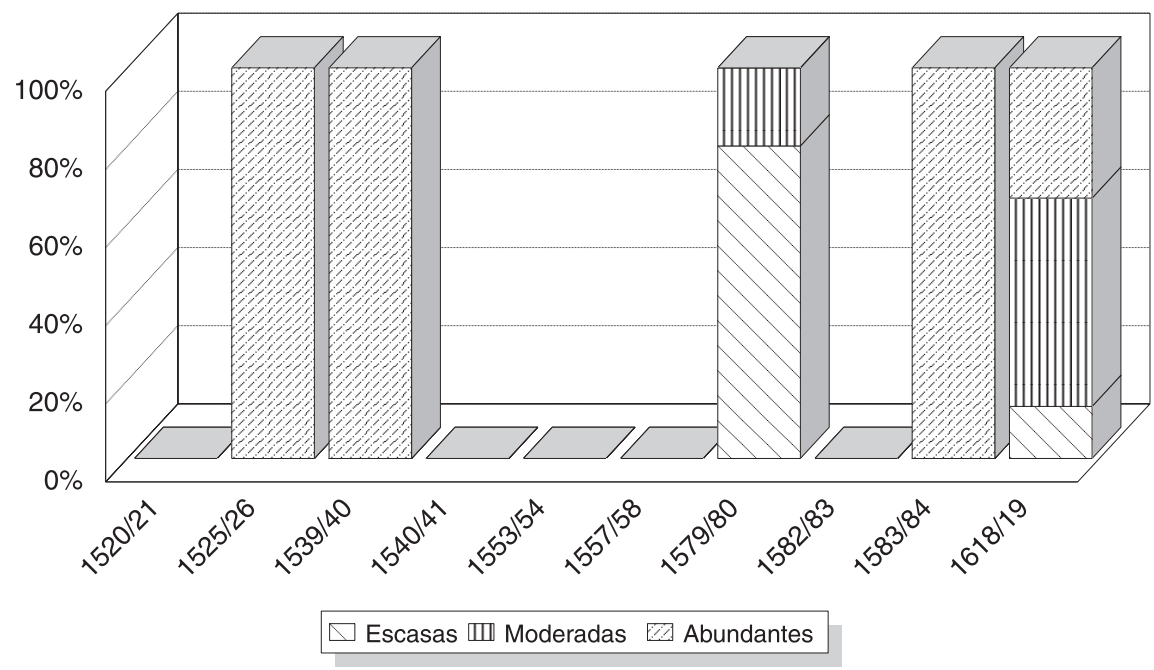

VERTIENTE OCCIDENTAL

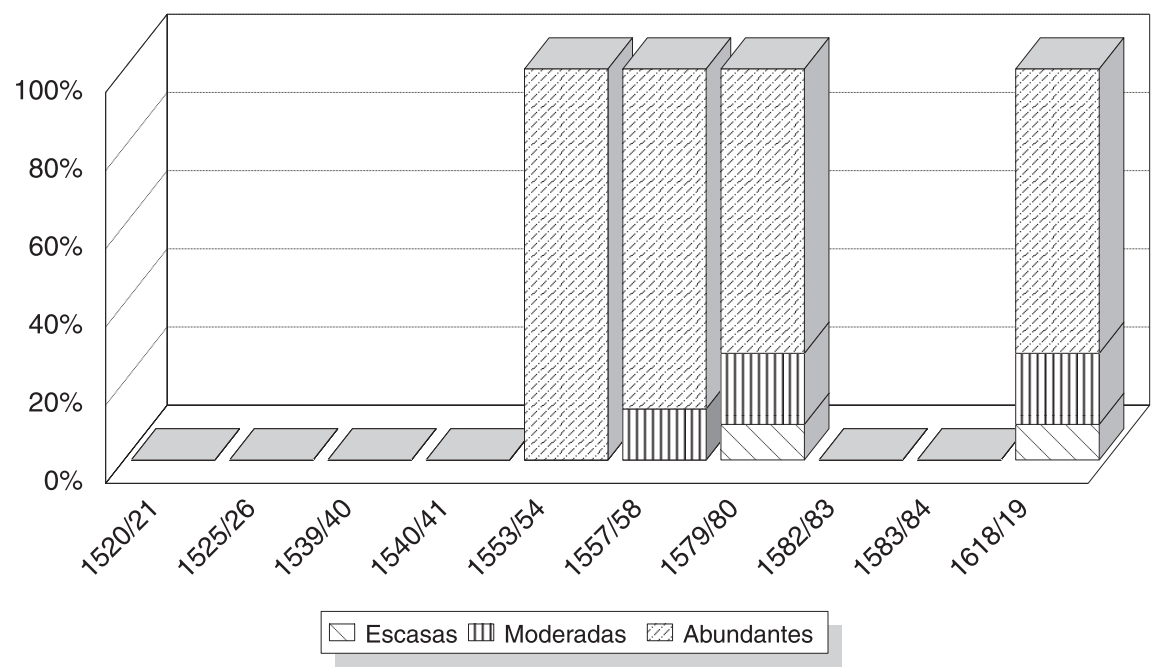

Fig. 4: Precipitaciones estivales en el área del Estrecho de Magallanes en el siglo XVI por clases (en porcentajes). 


\section{VERTIENTE ORIENTAL}

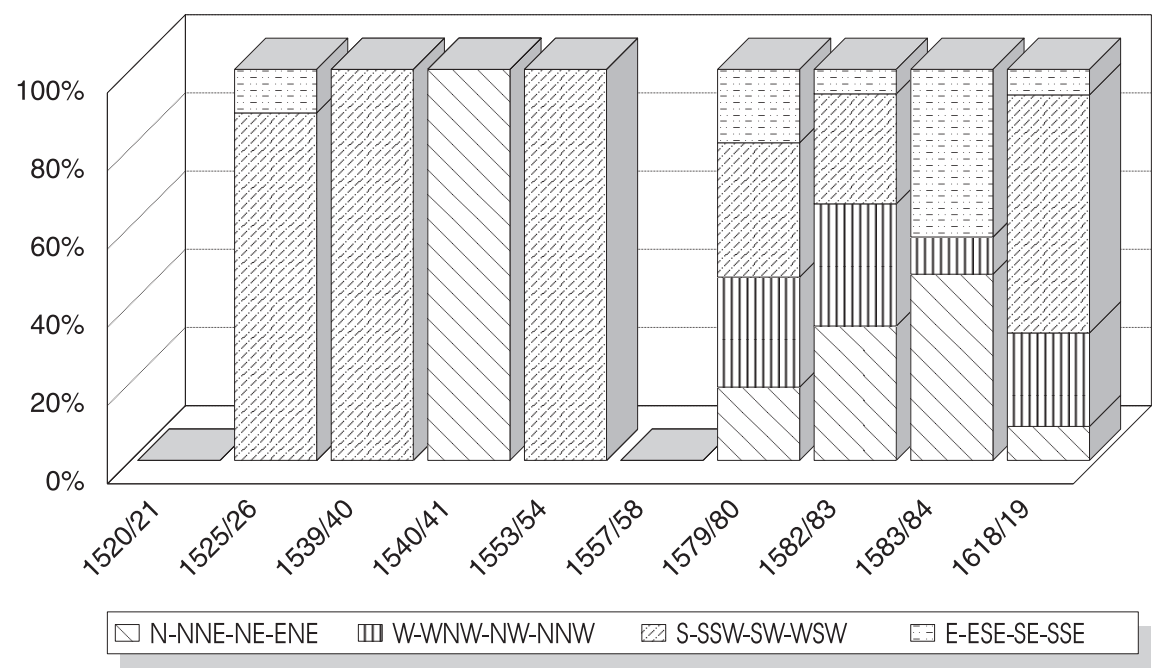

\section{VERTIENTE OCCIDENTAL}

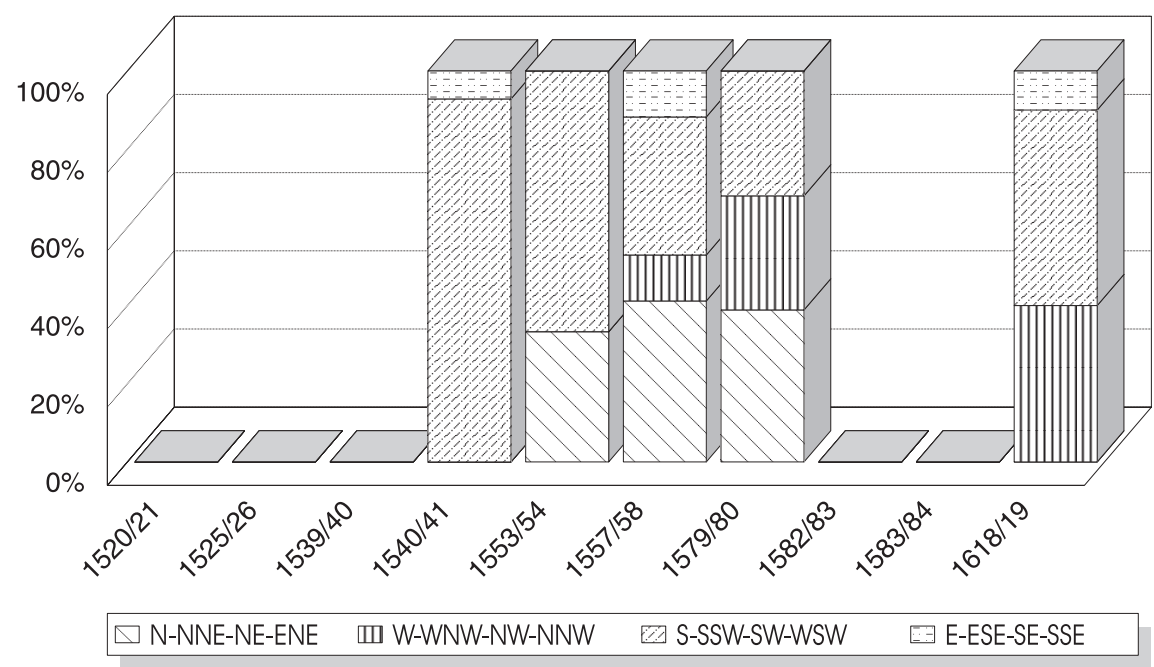

Fig. 5: Dirección de los vientos en la zona del Estrecho de Magallanes en el siglo XVI (en porcentajes). 


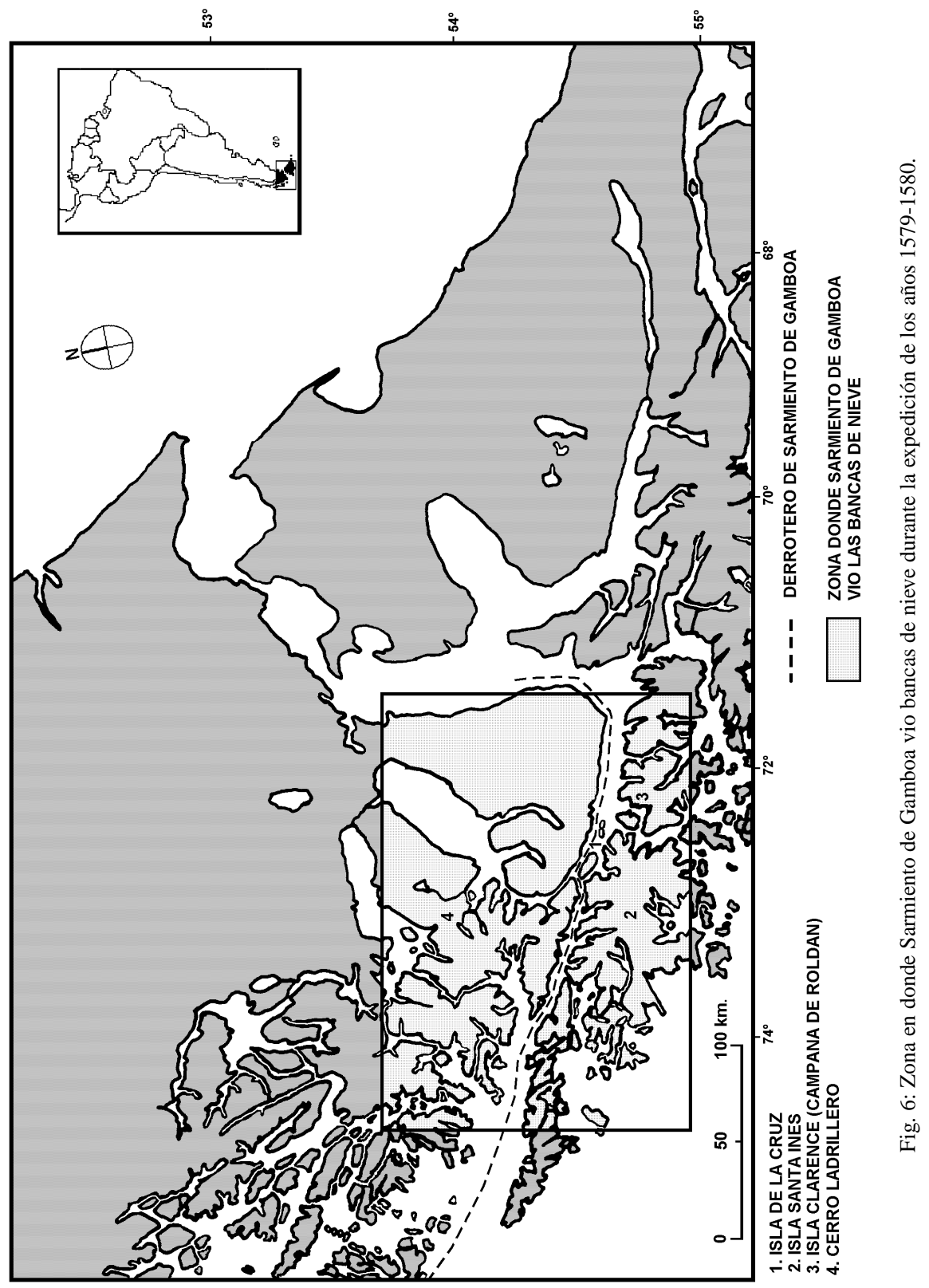

